\title{
Energy and Exergy Analysis of a Cogeneration Cycle, Driven by Ocean Thermal Energy Conversion (OTEC)
}

\author{
Jeffrey Ofosu-Adarkwa ${ }^{1}$, Tang $\mathrm{HaO}^{2}$ \\ ${ }^{1}$ College of Energy and Power Engineering, Nanjing University of Aeronautics and Astronautics Nanjing \\ 210016, China \\ ${ }^{2}$ College of Energy and Power Engineering, Nanjing University of Aeronautics and Astronautics Nanjing \\ 210016, China
}

Ocean Thermal Energy Conversion (OTEC) is a technology by which thermal energy from the ocean is harnessed and converted into electricity. It is one of the renewable energy technologies being researched into, as part of solutions to the challenge of global warming and climate change. A major setback of this technology, however, is that it has a very low cycle efficiency. In this work a cogeneration cycle is proposed which is driven by the temperature difference between the warm surface layer and the cold bottom layer of the ocean. The work is aimed at improving the overall cycle efficiency of OTEC systems by reducing the depth at which cold water is captured from the ocean. To achieve this, the cycle employs a binary mixture of ammonia and water as the working fluid and uses the mechanism of absorption to obtain the liquid phase of the working fluid after expansion through the turbine. The effects of varying cycle parameters such as the depth of cold-water capture, heat source temperature and mixture composition of the working fluid were investigated. With a basic solution mixture concentration of $0.40 \mathrm{~kg} / \mathrm{kg} \mathrm{NH} / \mathrm{H}_{2} \mathrm{O}$, and under operating conditions of $30^{\circ} \mathrm{C}$ as the warm surface water temperature and a cold water temperature of $10^{\circ} \mathrm{C}$, captured at a depth of $600 \mathrm{~m}$ the proposed cycle produced a net power output of $42 \mathrm{~kW}$, and a refrigeration capacity of $370 \mathrm{~kW}$. The thermal efficiency computed was $1.94 \%$ and the exergy efficiency was $13.78 \%$, both higher than the case where the depth of cold water capture was $1000 \mathrm{~m}$.

Keywords - cogeneration, combined cooling and power, efficiency, exergy, OTEC, vapor absorption cycles

Date of Submission: 12 March $2017 \quad$ Date of Accepted: 31 March 2017

\section{INTRODUCTION}

The primary source of power generation in the world today is derived from the combustion of fossil fuels such as oil, coal and natural gas. Increasing global population and technological advancement have lead to an ever-increasing energy demand. An adverse effect of the burning of fossil fuels is the emission of gases which are harmful to the environment. As a consequence, global warming has increased in the last decade. As a result, there have been frantic efforts from a wide range of stakeholders, from scientists to politicians to curb the situation and reduce the impact of global warming and climate change. These developments have lead to the intensification of investigation of alternative energy resources and technologies which produce very little or zero emissions that contribute to global warming. Ocean Thermal Energy Conversion (OTEC) is one of the renewable technologies which is increasingly gaining worldwide recognition. OTEC is a renewable energy technology that converts heat energy into electricity and other useful forms by making use of the temperature difference between the warm upper surface layer and the cold bottom layer of the ocean.
The OTEC technology employs the thermodynamic concept of placing a heat engine between two reservoirs (hot and cold), such that the hot reservoir supplies heat to a thermodynamic cycle which produces work and then rejects the heat to the cold reservoir. In the case of OTEC, the upper layer (about $100 \mathrm{~m}$ deep) of the ocean at a temperature of approximately $25-30^{\circ} \mathrm{C}$ serves as the heat source (hot reservoir) and cold water drawn from the bottom of the ocean (about $700-1000 \mathrm{~m}$ deep) at a temperature of approximately $5-10^{\circ} \mathrm{C}$ serves as the heat sink (cold reservoir)[1]. The ability of this technology to achieve power generation with thermal energy from the ocean without the burning of any fuel is what makes it very appealing especially with respect to environmental impact, and the use of a constantly renewable resource. However, a major setback of OTEC technology is that, the temperature difference $\Delta \mathrm{T}$, between the surface layer and the bottom layer of the ocean, which is the driving force for OTEC, is very small $\left(\sim 20^{\circ}\right)$ and as such leads to a very low thermal efficiency, which is a constraint to its economic viability[1]. 
The basic configuration of a closed-cycle OTEC system operates on the same principle of the Rankine Cycle which is operated by conventional steam-driven thermal power plants. The difference lies in the operating temperatures. Whereas steam thermal plants require a heat source temperature of over $100^{\circ} \mathrm{C}$ to operate efficiently, the heat source temperature for OTEC is just about $25^{\circ} \mathrm{C}$ to $30^{\circ} \mathrm{C}$ supplied by the surface layer of the ocean. As a result of this operating temperature, the suitable working fluids for OTEC are organic fluids and other working fluids which have low saturation temperatures. Thus the thermodynamic cycle that is usually operated by closed cycle OTEC systems is the Organic Rankine Cycle. Sun et al.[2] performed an exergy analysis and evaluated the cycle performance, comparing results for an OTEC-driven Organic Rankine Cycle, in which R717 and R134a were used as the working fluids. the cycle was optimized to achieve maximum net power output and the working fluid R717 produced highly desirable results as the most suitable working fluid. an experimental study of the closed-cycle OTEC system was carried out by Faizal and Ahmed[3].Results from their study indicated a maximum thermal efficiency of approximately $1.5 \%$ when $\mathrm{R} 134 \mathrm{a}$ was used as the working fluid. The net power output and efficiency increased proportionally with the ratio of warm water to cold water flowrates. Their study also pointed out that both the thermal efficiency and the power output of the system increased by increasing the temperature difference between warm and cold seawater. One way of increasing this temperature difference is by increasing the temperature of the heat by using solar heat energy [4, 5] and the waste heat from the condenser of existing thermal power plants.

Another technique that is effective in improving cycle efficiency involves the integration of other components such as a regenerator to the cycle to maximize the utilization of the available heat resource. Wang et al.[6] carried out experiments using a regenerative $\mathrm{ORC}$ system with $\mathrm{R}-123$ as the working fluid and geothermal heat source at $130^{\circ} \mathrm{C}$, and compared the performance to that of a basic ORC system. The results showed that the regenerative system had an efficiency about 1.3 times higher than that of the basic ORC.

Further improvements to the organic rankine cycle lead to the development of other thermodynamic cycles such as the Kalina cycle and the Goswami cycle. The main distinguishing feature of the Kalina cycle is the use of a binary mixture as the working fluid. The advantage of a binary mixture working fluid is that the phase transitions during the evaporation and condensation process occur at a variable range of temperatures. The individual boiling and condensation temperatures of the mixture components are different, and as such, during evaporation at a constant pressure and a particular composition, the more volatile component starts to vaporize. The vaporization starts from the saturation temperature of the more volatile component and then continues through to the saturation temperature of the less volatile component. This creates what is referred to as a temperature glide and provides a better thermal matching between the heat source and the working fluid. This reduces the heat transfer irreversibility, thereby contributing to improved cycle thermal efficiency. The use of binary mixture working fluids in absorption power cycles such as the Maloney-Robertson cycle and the Kalina cycle, as well as vapor-absorption refrigeration cycles inspired a new type of combined power and cooling cycle, proposed by Dr. Yogi Goswami. In the Goswami cycle, the feed stream of the working fluid is obtained through absorption of the vapor by a liquid solution rather than the usual type of condensation used in conventional cycles. When the usual mode of condensation is used, the minimum pressure and temperature at which the expanding vapor exits the turbine is limited by the temperature at which condensation occurs for the working fluid. On the other hand, when absorption-condensation is used, the vapor exiting the turbine can be expanded to temperatures below ambient pressure, with corresponding low temperatures, without necessarily being limited by the condensing temperature, resulting in very cool vapor. This technique when applied to OTEC systems would provide the benefit of not having to go as deep as $1000 \mathrm{~m}$ for cold deep seawater. In essence, pumping cold deep seawater from as deep as $1000 \mathrm{~m}$ consumes a very large amount of the energy produced (about one-third) and also requires equipment which come at very huge costs. This work presents a cogeneration cycle that will reduce the depth of cold water capture, which will in effect reduce pump energy consumption and improve overall cycle efficiency.

\section{MATERIALS AND METHODS}

1.1 Modelling of Proposed Cycle

A model of the proposed cycle was simulated to provide a basis for the evaluation of the various performance indicators of the system. The simulation was performed using ASPEN Plus $\AA$, which is a commercial computer program that is used to model thermodynamic processes. The properties of the ammonia-water mixture and other fluids used in this study were obtained from the NIST database which is also available on the ASPEN Plus ${ }^{\circledR}$ program. The fluid properties were also verified from REFPROP® and the Soave-Redlich-Kwong (SRK) Equation of State was employed as the property method. 


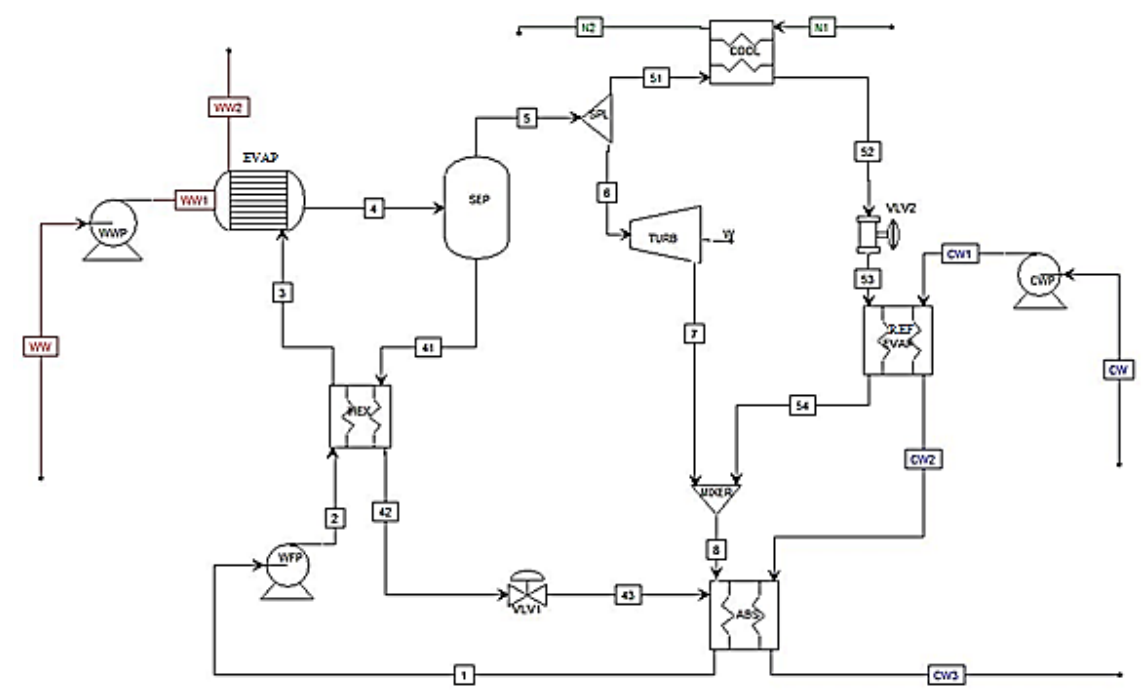

Figure 1 A schematic diagram of the proposed cogeneration cycle

A schematic diagram of the proposed cycle configuration is shown in Fig.1. It can be described as a combination of a vapor absorption power cycle and a vapor absorption refrigeration cycle. The system is controlled by two pressure levels i.e. the high pressure at the boiler and the low pressure at the absorber. The high pressure and the low pressure represent the pressures at which the phase transition processes of vaporization and condensation take place respectively. The cycle begins with a mixture of ammonia and water $\left(\mathrm{NH}_{3} / \mathrm{H}_{2} \mathrm{O}\right)$ with a specific composition. This is referred to as the basic solution (state 1). A solution pump is used to increase its pressure to the system high pressure (state 2). This stream then passes through an internal heat exchanger (IHE) where it recovers heat from the weak solution (state 41) that returns from the separator after the separation of rich $\mathrm{NH}_{3}$ vapor. The preheated stream (state 3) goes through the boiler, where it is boiled by the heat source which is the surface sea water. Partial vaporization occurs in the boiler, which results in a two-phase, vapor-liquid mixture (state 4), which is then further separated in the separator. The separation process results two streams. One is a vapor stream which has a very high concentration of NH3 (state 5), and the other is the weak solution (state 41). The weak solution is throttled to the system low pressure and subsequently to the absorber.

The rich $\mathrm{NH}_{3}$ vapor on the other hand, is split into two streams, (state 51) and (state 6). The stream with parameters as at state 6 is the stream that drives the power generation part of the cycle. It is expanded to low pressure (state 7) through the turbine, thereby generating a power output. The other $\mathrm{NH}_{3}$-rich vapor stream (state 51), on the other hand drives the refrigeration part of the combined cycle. It is first condensed (state 52) after which it is throttled to the system low pressure (state 53). At this state it is very cold liquid which serves as the refrigerant when passed through an evaporator. At the evaporator, the cold sea water which has a relatively higher temperature than the ammonia-rich refrigerant is made to provide sensible heating to vaporize the ammoniarich refrigerant (state 54). The vapor streams (state 7) and (state 54) mix together and are absorbed by the weak solution (state 43) to reform the basic solution (state 1) in the absorber.

\subsection{Mass and Energy Balance}

The simulation of the proposed cycle and the subsequent thermodynamic analyses are based on energy and mass balance equations as well as assumption of certain conditions which simplify the equations. The key operating conditions and assumptions that were made with respect to the simulation of the proposed cycle are as follows. Energy and mass balance calculations are done on the components by taking each component as a control volume under steady state operation. The conditions for boiling are specified by entering boiling temperature, pressure, and basic solution concentration as inputs. The minimum absorption temperature and the concentration of the basic solution are also specified. The pump and turbine are assumed to have isentropic efficiencies of 0.85 each, and heat losses and pressure drops are neglected. The reference temperature, $\mathrm{T}_{\mathrm{o}}$ is taken to be $298.15 \mathrm{~K}$. The mass balance and energy balance equations are represented by the equations (1) - (12).

$$
\begin{aligned}
& \Delta \Sigma_{\text {out }}^{\text {in }} m_{i}=0 \\
& \Delta \Sigma_{\text {out }}^{\text {in }} X_{i} \times m_{i}=0 \\
& Q_{\text {EVAP }}=\dot{m}_{3}\left(h_{4}-h_{3}\right) \\
& Q_{E V A P}=m_{w W}^{*}\left(h_{w w 1}-h_{w w 2}\right) \\
& Q_{I H E}^{*}=\dot{m}_{2}\left(h_{2}-h_{2}\right) \\
& Q_{I H E}^{*}=m_{41}^{*}\left(h_{41}-h_{42}\right) \\
& Q_{C O N}^{*}=\dot{m}_{2}\left(h_{51}-h_{52}\right)
\end{aligned}
$$




$$
\begin{aligned}
& Q_{C O N}^{*}=m_{N 1}^{*}\left(h_{N 2}-h_{N 1}\right) \\
& Q_{E V A P}^{*}=m_{53}\left(h_{54}-h_{53}\right) \\
& Q_{E V A P}=m_{c w 1}^{*}\left(h_{c w 1}-h_{c w 2}\right) \\
& Q_{A B S}^{*}=\dot{m}_{1}\left(h_{8}-h_{1}\right) \\
& Q_{A B S}=m_{c w 2}^{*}\left(h_{c w 3}-h_{c w 2}\right) \\
& W_{p}=\frac{\dot{m}_{1} v_{1}}{\eta_{p}}=\left(P_{2}-P_{1}\right)
\end{aligned}
$$

\subsection{Performance Evaluation of Cogeneration Cycle}

Since the output of the combined cycle consists of two different quantities, i.e. power and refrigeration, whose efficiencies are computed differently. Evaluating the efficiency of the combined cycle simply as a ratio of the sum of outputs to the heat input would be erroneous and would overestimate the efficiency of the cycle. In order to address this issue, Vijayaraghavan and Goswami [7] developed new expressions which are more appropriate and thermodynamically consistent in representing the efficiency of the combined power and cooling cycle. These new expressions account for the quality of heat available for the refrigeration part of the cycle. This is accomplished by replacing the cooling output of the cycle by the exergy associated with the cooling output, thus making it possible to add the refrigeration output to the power output in a single efficiency expression as follows:

$$
\begin{array}{ll}
\eta_{\text {th }}=\left(W_{\text {net }}+E_{c}\right) / Q_{h s} \\
\eta_{\text {exergy }}=\left(W_{\text {net }}+E_{c}\right) /\left(E_{h s, \text { in }}-E_{\text {hs,out }}\right) \\
E_{c}=\dot{m}\left[h_{\text {coolin }}-h_{\text {cool, out }}-T_{o}\left(S_{\text {cool, in }}-S_{\text {cool }, \text { out }}\right)\right]
\end{array}
$$

The performance of the combined cycle can be evaluated consistently using the expressions in (13) and (14). However, these definitions, in themselves are not appropriate when we need to compare the combined cycle to other thermodynamic cycles. For instance, to compare this combined cycle to a power cycle, we would have to configure the combined cycle to operate as a power cycle, and as such, the refrigeration output would have to be weighted differently in order to be able to make a valid comparison. One way to achieve this, is by dividing the exergy of cooling by the COP of a reversible refrigeration cycle, which is a Lorentz cycle in this case. This implies replacing the cooling output by the minimum mechanical power required to produce the same amount of cooling that would be achieved by a reversible refrigeration cycle. The resulting expression, as reported by Vijayaraghavan and Goswami, is referred to as effective efficiency, shown below [8-10]:

$$
\eta_{t h, e f f}=\frac{\left(W_{n e t}+E_{c} / C_{C O P_{R e v}}\right)}{Q_{h s}}
$$

$$
\eta_{\text {exergy,eff }}=\frac{\left(W_{\text {net }}+E_{c} / \operatorname{COP}_{\text {Rev }}\right)}{\left(E_{h s, \text { in }}-E_{h s, o u t}\right)}
$$

In practical applications, however, the same cooling output would require relatively higher amount of power input due to certain internal and external irreversibilities associated with real refrigeration cycles. A more realistic approach would be to divide the exergy of cooling by a reasonable second law efficiency for a refrigeration cycle. This is equivalent to dividing by a practical COP rather than the reversible COP.

\subsection{Exergy Analysis}

Exergy analysis was performed on the combined cycle in order to determine the sources of irreversibility which leads to losses in the cycle. This was done by modelling each component as a control volume and then using the exergy balance equation to calculate the exergy destruction (irreversibility) for each component. The exergy destroyed represents the energy that could have been converted to work but was rather wasted, thus it is desirable to keep the exergy destroyed as minimal as possible. The determination of the exergy destruction at various components of the cycle is important as it points one to aspects of the cycle that need to be improved in order to reduce losses and improve the overall efficiency of the cycle. The overall exergy balance is expressed by the equation:

$\frac{d E}{d t}=\Sigma\left(1-\frac{T_{o}}{T}\right) Q_{C V}^{*}-W_{C V}^{*}+P_{o} \frac{d V}{d t}+\Sigma\left(E_{\text {in }}-E_{o u t}\right)-T_{o} S_{g e n}^{*}$

The term $T_{0}\left(S_{\text {gen }}\right)^{\prime}$ is what is termed the irreversibility or the exergy destroyed and is denoted $\mathrm{Ed}$, for purposes of this study. The exergy destroyed at the various components of the system were computed from simplifying the above expression (18) using the assumptions listed in section 2.2. for the thermodynamic analysis.

\section{RESULTS AND DISCUSSION}

\subsection{Effect of Heat Source Temperature}

In the basic configuration of the proposed cycle, the heat source which is warm surface seawater is supplied to the evaporator at an inlet temperature of $25^{\circ} \mathrm{C}$. However, this inlet temperature can be increased by other techniques such as using solar collectors or using effluent heat streams from existing thermal plants as mentioned previously. Simulations were performed to evaluate the cycle's performance and observe the effect of increasing the heat source temperature. The key operating conditions that were used in simulating the proposed cycle are summarized in Table 1. These simulations were done with the assumption that the temperature of the warm sea water was increased to 30,35 and $40^{\circ} \mathrm{C}$, by one of the techniques mentioned earlier. The results produced are summarized in Table 2 and shows an increasing 
trend for the cycle's performance as the heat source temperature increased. A plot to illustrate this relationship is shown on Fig. 2. The work output (net power) as well as the cooling output increased as the heat source temperature was increased.

Table 1 Summary Of Operating Conditions for Simulation

\begin{tabular}{|l|l|l|}
\hline Parameter & Unit & Value \\
\hline Reference Temperature $\left(\mathrm{T}_{\mathrm{o}}\right)$ & $\mathrm{K}$ & 298.1 \\
Evaporator pressure $\left(\mathrm{P}_{\mathrm{EVAP}}\right)$ & $\mathrm{bar}$ & 5 \\
\cline { 2 - 2 } Absorber pressure $\left(\mathrm{P}_{\mathrm{abs}}\right)$ & $\mathrm{bar}$ & 8.0 \\
Mass flowrate of working fluid $(\mathrm{m})$ & $\mathrm{kg} / \mathrm{s}$ & 5.0 \\
Ammonia mass fraction $(\mathrm{X})$ of basic & $\mathrm{kg} / \mathrm{kg}$ & 10 \\
solution & $\mathrm{NH}_{3}$ & 0.40 \\
Warm water inlet temperature $\left(\mathrm{T}_{\mathrm{ww}}\right)$ & ${ }^{\circ} \mathrm{C}$ & 30 \\
Cold water inlet temperature $\left(\mathrm{T}_{\mathrm{cw}}\right)$ & ${ }^{\circ} \mathrm{C}$ & 10 \\
Pump Isentropic efficiency & & 0.85 \\
Turbine Isentropic efficiency & & 0.85 \\
\hline
\end{tabular}

Table 2 Cycle Performance Summary at Heat Source Temperature of $30^{\circ} \mathrm{C}$

\begin{tabular}{|l|l|l|l|}
\hline Parameter & Unit & CASE I & CASE II \\
\hline Depth of Ocean & $\mathrm{m}$ & 1000 & 600 \\
\hline $\begin{array}{l}\text { Turbine Work output } \\
(\mathrm{W})\end{array}$ & $\mathrm{kW}$ & 137 & 137 \\
\hline Pump work $\left(\mathrm{W}_{\text {pump}}\right)$ & $\mathrm{kW}$ & 134 & 95 \\
\hline $\begin{array}{l}\text { Net Power output } \\
\left(\mathrm{W}_{\text {net }}\right)\end{array}$ & $\mathrm{kW}$ & 3 & 42 \\
\hline $\begin{array}{l}\text { Refrigeration output } \\
\left(\mathrm{Q}_{\mathrm{c}}\right)\end{array}$ & $\mathrm{kW}$ & 370 & 370 \\
\hline $\begin{array}{l}\text { Exergy of Cooling } \\
\left(\mathrm{E}_{\mathrm{c}}\right)\end{array}$ & $\mathrm{kW}$ & 26 & 26 \\
\hline $\begin{array}{l}\text { Evaporator Heat } \\
\text { input }\left(\mathrm{Q}_{\mathrm{h}}\right)\end{array}$ & $\mathrm{MW}$ & 3.5 & 3.5 \\
\hline $\begin{array}{l}\text { Exergy at evaporator } \\
\left(\mathrm{E}_{\mathrm{hs}}\right)\end{array}$ & $\mathrm{kW}$ & 534 & 534 \\
\hline $\begin{array}{l}\text { Thermal efficiency } \\
\left(\eta_{\text {th }}\right)\end{array}$ & $\%$ & 0.38 & 1.94 \\
\hline $\begin{array}{l}\text { Exergy efficiency } \\
\left(\eta_{\text {exergy }}\right)\end{array}$ & $\%$ & 3.81 & 13.78 \\
\hline
\end{tabular}

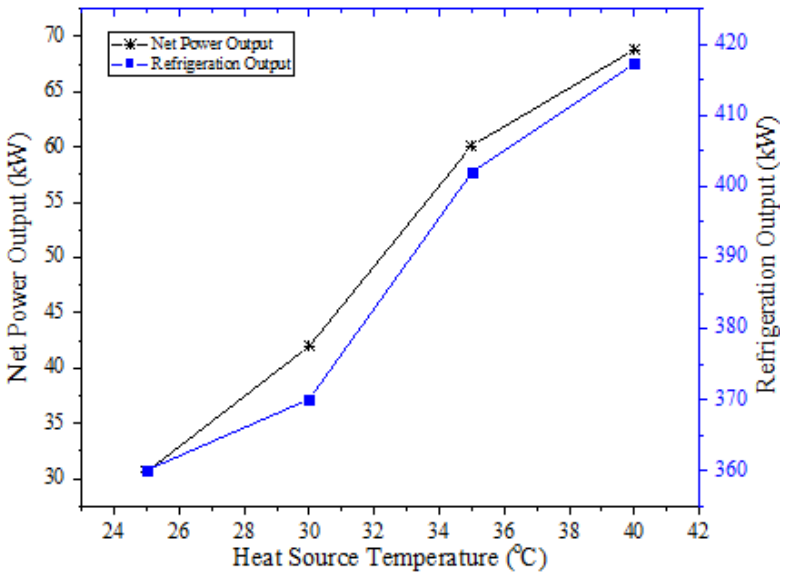

Figure 2 Effect of The Heat Source Temperature on The Cycle Outputs

\subsection{Effect of Mixture Composition}

A very important characteristic for all binary-mixture working fluids is the concentration of the mixture.
This characteristic has a direct impact on the saturation temperatures as well as the temperature glide of the working fluid. As has been explained in the previous sections, the construction of the bubble and dew point lines, which represent the phase transition from the liquid state to the vapor state and vice versa, depend on the concentration of the mixture and the pressures at which the process take place. Similar to the pressure at which boiling occurs, the mixture concentration has lower and upper limits. The lowest possible concentration corresponds to the concentration that saturation occurs at the given temperature and pressure. This implies that a mixture having a concentration below the lower limit will not be able to boil at the specified temperature. In a similar manner, the concentration of the basic solution determines the absorption pressure. At a point where the saturation pressure becomes equal to the boiling pressure, the mixture concentration would have attained its maximum value.

For this study, the concentration of the basic solution

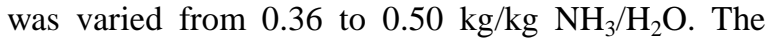
simulation results indicated a general increase in the cycle outputs as the composition of ammonia in the mixture was varied incrementally from 0.36 . This is mainly due to the fact that increasing the mass fraction of ammonia in the mixture implies increasing the mass fraction of the more-volatile substance. Since the more-volatile substance has a lower boiling point, the higher its composition, the higher the amount of vapor that is formed (Fig. 3 and Fig. 4), and since it is the formation of the vapor that drives the cycle's outputs, the increase in the formation of vapor corresponds to an increase in the cycle outputs.

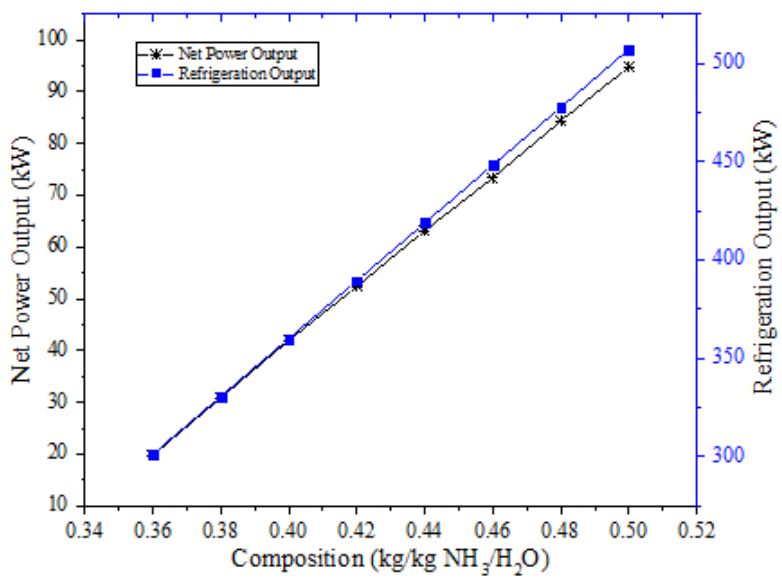

Figure 3 Effect of Mixture Concentration on The Cycle Outputs 


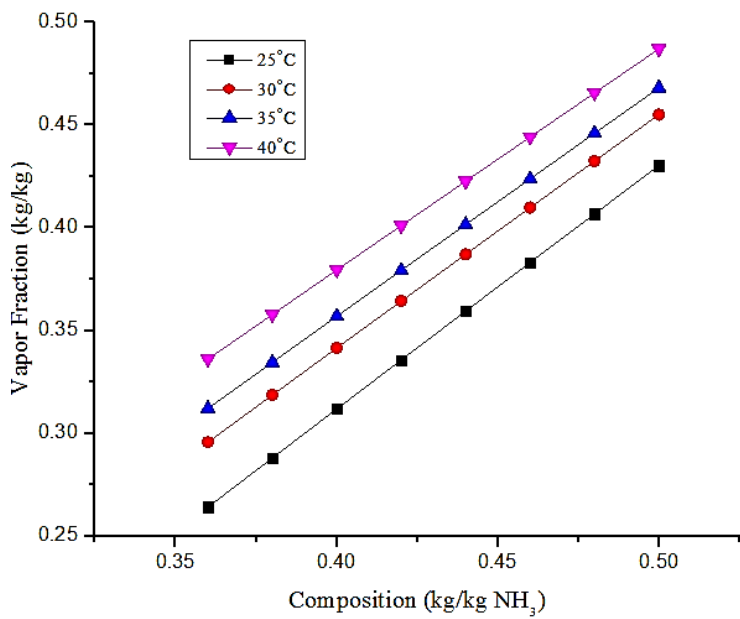

Figure 4 Effect of Composition on The Vapor Fraction at Varying Heat Source Temperatures

\subsection{Pump Power Input}

Two cases were simulated with respect to the depth of the ocean and their performance characteristics were evaluated. Case I represented the situation where the cold water is captured at a depth of $1000 \mathrm{~m}$ beneath the ocean surface. This depth corresponded to a cold water temperature of approximately $5^{\circ} \mathrm{C}$. Case II on the other hand represented the situation whereby the proposed cogeneration cycle makes it possible for the depth of cold water capture to be reduced to $600 \mathrm{~m}$ beneath the ocean surface layer. Comparison between the simulation results of these two cases indicated that Case II produced higher net power outputs and cycle efficiencies than Case I. This is explained by Fig. 5 which shows the effect of the depth of cold water capture on the power input required by the pump. The figure is plotted from (19) and shows a directly proportional relationship between the ocean depth and the power required to pump water from the corresponding depth to the ocean surface layer where the OTEC plant is installed.

$$
P_{h}=\frac{q \rho g h}{3.6 * 10^{6}}
$$

Where $P_{h}$ is the hydraulic power in kilowatts $(\mathrm{kW}), \mathrm{q}$ is the flow capacity in cubic meters per hour $\left(\mathrm{m}^{3} / \mathrm{h}\right), \rho$ is the density of water in kilograms per cubic meters $\left(\mathrm{kg} / \mathrm{m}^{3}\right), \mathrm{g}$ is the acceleration due to gravity $(9.81$ $\mathrm{m} / \mathrm{s}^{2}$ ) and $\mathrm{h}$ is the ocean differential head in meters (m).

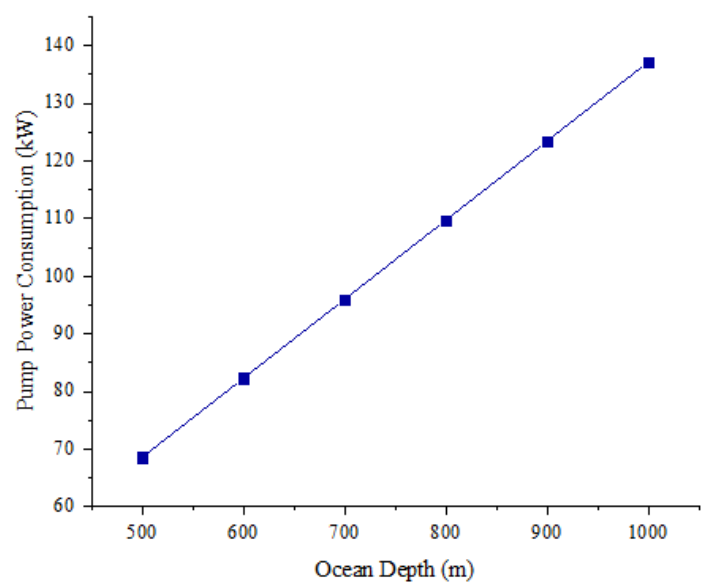

Figure 5 Relationship between Ocean Depth of Cold Water Capture and Pump Power Input

\subsection{Effect of Split Fraction}

The splitter serves the primary purpose of splitting the ammonia-rich vapor into two streams which are the driving forces behind the absorption power and the absorption refrigeration parts of the cycle. Since the cycle employs the use of a splitter to obtain the two vapor streams, the split fraction that is used plays an important role in determining how much power or cooling output is obtained. As such, the split ratio was varied according to $\mathrm{a}: \mathrm{b}=0.5: 0.5, \mathrm{a}: \mathrm{b}=0.4: 0.6, \mathrm{a}: \mathrm{b}=$ $0.3: 0.7, a: b=0.2: 0.8$ and $a: b=0.1: 0.9$, where "a" represents the fraction of vapor that goes to refrigeration part and " $b$ " represents the fraction of vapor that goes to the power generation part. The identifications SPL_F1, SPL_F2, SPL_F3, SPL_F4, and SPL_F5 were given for the various split fractions which correspond to $0.5: 0.5,0.4: 0.6,0.3: 0.7,0.2: 0.8$ and 0.1:0.9 respectively. The Fig. 6a shows that as the fraction "a" which corresponds to the vapor set aside for the refrigeration part decreased from 0.5 to 0.1 , the refrigeration output decreased. While "a" decreased, " $b$ " increased from 0.5 to 0.9 which corresponds to an increase in the fraction of the vapor designated to expand in the turbine to generate the power output. This lead to an increase in the power output (Fig. 6b) The optimum split ratio for the cycle was chosen to be $\mathrm{a}: \mathrm{b}=0.1: 0.9$, since this ratio gave the maximum power output. 


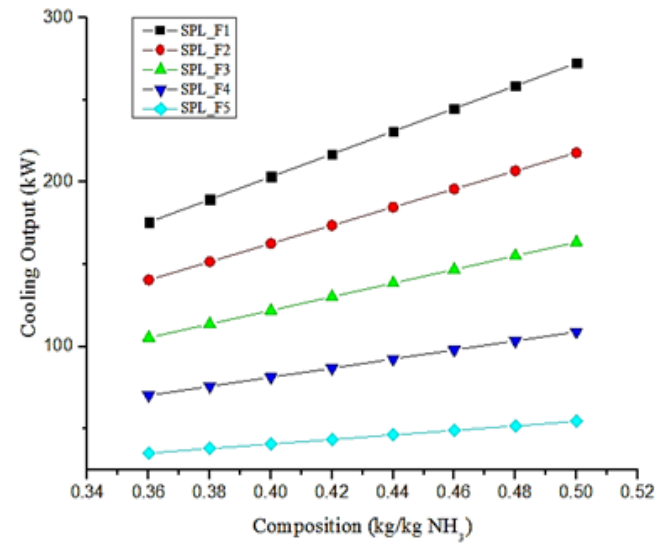

a) Cooling Output

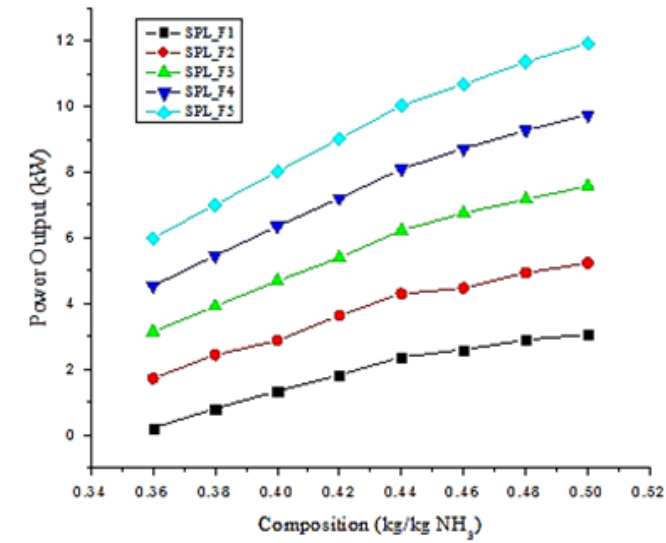

b) Power Output

Figure 6 Effect of Split Fractions on The Cycle Outputs

\subsection{Overall Cycle Efficiency 3.5.1 Thermal Efficiency}

A very important parameter for every device that makes use of thermal energy is the thermal efficiency, $\eta_{\text {th. }}$ Often referred to as "1st Law efficiency" or simply efficiency, it is a straightforward representation of the cycle's performance based on the conditions of the heat transfer mechanisms in the cycle's heat exchangers. For power cycles, it gives an indication of the extent to which the heat energy provided to the cycle is converted to the net work output. For absorption refrigeration cycles, on the other hand, it gives an indication of the amount of cooling that is produced from the heat added to the cycle and is referred to as the coefficient of performance (COP). The thermal efficiency of the proposed combined cycle was computed according to (13) and (15), using results from the simulation. Different concentrations of the basic solution of the binary mixture working fluid were investigated to observe the effect on the thermal efficiency. The heat source temperature was also varied to observe the effect it has on the thermal efficiency. Also, the trend for the thermal efficiency was observed for different split fractions of the ammonia-rich vapor. Fig. 7 shows that the thermal efficiency of the cycle portrays a steady increase as the heat source temperature increases. This is due to the fact that there is an increase in the extent to which vapor formation in the evaporator occurs when the heat source temperature is increased.

\subsubsection{Exergy Efficiency}

A limitation of the first law (thermal) efficiency, is its inability to reflect all the irreversible losses due to the fact that it does not account for the quality of heat through the cycle. The 2nd law of thermodynamics, however, accounts for the increase in entropy that takes place during temperature change. The increase in entropy leads to irreversibility and as such lead to energy losses in a process. The term exergy is a consequence of the 2nd Law and refers to the maximum useful work that is possible to be done by a process that brings a system into equilibrium with a heat reservoir. In this regard, exergy efficiency or second law efficiency refers to a ratio of the desired output to the useful input and thus a measure of the fraction of the exergy going into the cycle that comes out as useful output.

The expressions for the exergy efficiency of the proposed combined cycle (14) and (15) were used to compute the exergy efficiency using the results from the simulation. The influence of cycle parameters such as heat source temperature, basic solution concentration and split fraction on the exergy efficiency was investigated. When different heat source temperatures were applied to the cycle, the exergy efficiency increased with increasing heat source temperature. In comparison with the thermal efficiency, the exergy efficiency of the cycle indicated higher values as expected (Fig.7). The influence of the variation in concentration of the basic solution on the exergy efficiency was also investigated. Fig. 8 shows that as the composition is increased, the exergy efficiency increases steeply until a concentration of $0.40 \mathrm{NH}_{3}$, after which the increment is gradual. This is mainly due the nature of the $\mathrm{NH}_{3}-\mathrm{H}_{2} \mathrm{O}$ enthalpyconcentration diagram (Fig. 9). The figure shows that at a fixed pressure, and with an increasing concentration, the liquid enthalpy gradually decreases initially, and then reaches a point of inflection where it starts to increase. The initial compositions at which there is a decrease in the enthalpy lead to a corresponding decrease in the exergy of the heat source $\left(\mathrm{E}_{\mathrm{hs}}\right)$. From (14), since $\eta_{\text {exergy }}$ and $\Delta E_{\text {hs }}$ are inversely proportional, when the exergy change of the heat source decreases, the exergy efficiency increases and vice versa. 


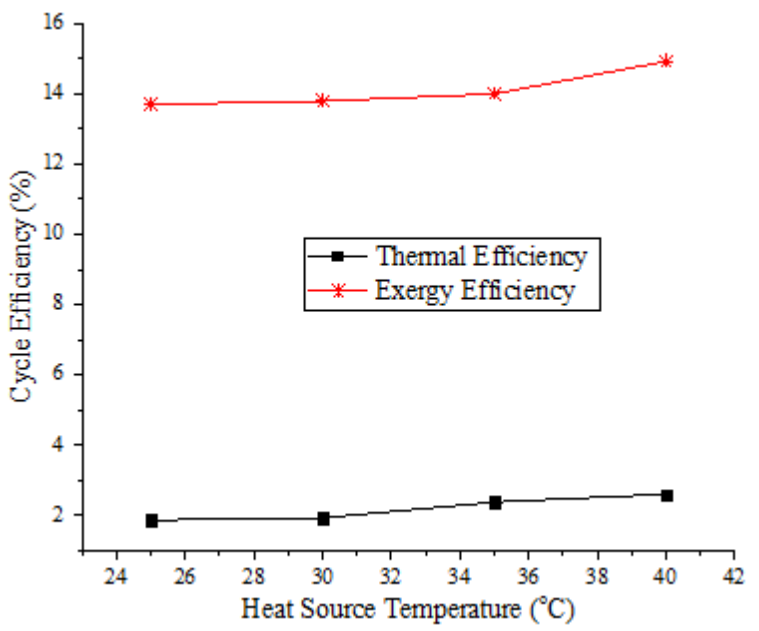

Figure 7 Effect of The Heat Source Temperature on The Cycle Efficiency

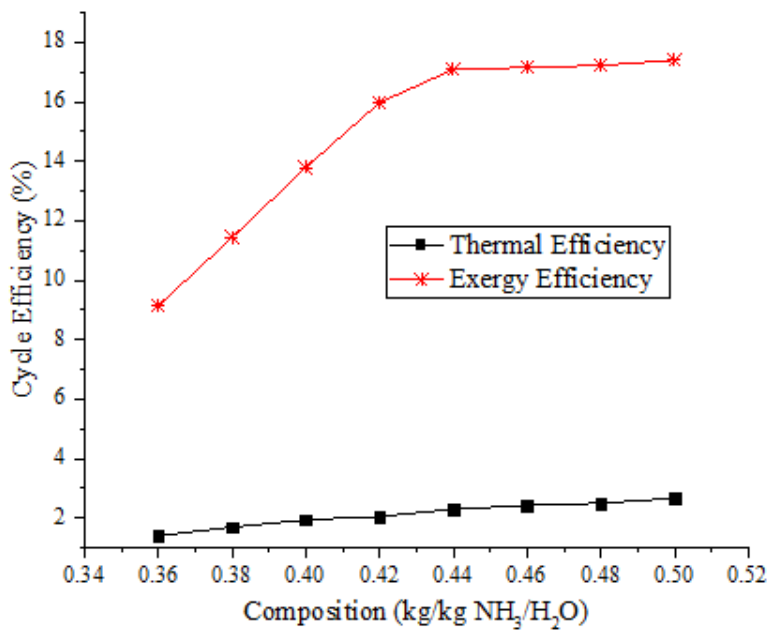

Figure 8 Effect of The Mixture Concentration on The Exergy Efficiency of The Cycle

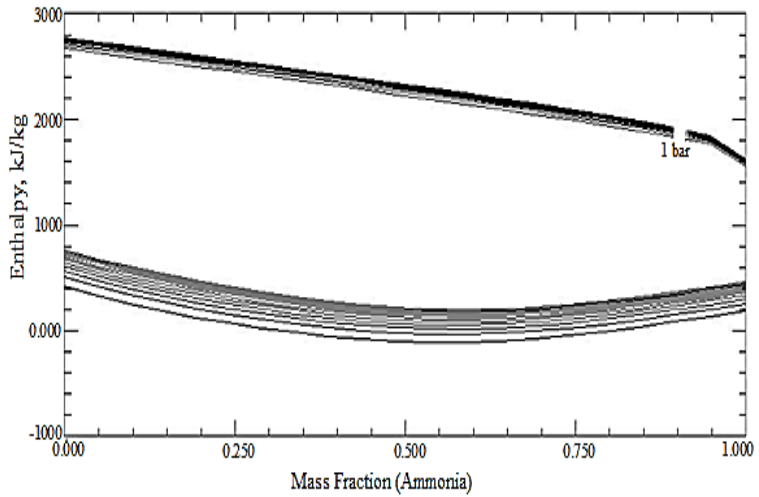

Figure 9 Effect of Enthalpy-Concentration Curves of $\mathrm{NH}_{3} / \mathrm{H}_{2} \mathrm{O}$ Mixture (5 - 8 bar)

\subsection{Exergy Analysis}

The Exergy analysis performed on the combined cycle enabled the determination of sources of irreversibility in the cycle. Each component was assumed as a control volume and then exergy balance equations were used to calculate the exergy destruction (irreversibility) for each component. Fig. 10 shows a comparison between the exergy destruction rates of the components of the proposed cogeneration system and a conventional power cycle. As illustrated in the chart, the highest rate of exergy destroyed is at the turbine of the conventional power cycle. This can be attributed to the fact that the working fluid which is highly rich in $\mathrm{NH}_{3}$ in this case is not allowed to expand to pressures below ambient conditions. That would require extremely low temperatures for condensation to occur. This situation is avoided at the expense of the power output that could be produced if the vapor were allowed to expand further to low pressures. This contributes to a large amount of exergy destruction. It can be seen that this is not the case for the turbine in the cogeneration cycle, since the process of absorption helps to deal with this issue. The absorber is the component with the second highest rate of exergy destruction, followed by the evaporator. Generally, the components of the cogeneration cycle contributed less to the total exergy destroyed than those of the conventional power cycle. The importance of exergy analyses with the determination of the exergy destruction at various components of the cycle is evident in the fact that it highlights the parts of the cycle that generate very high irreversibilities, such that if modifications need to be made to improve the performance of the system, those areas that contribute the highest irreversibilities are the first places to look at.

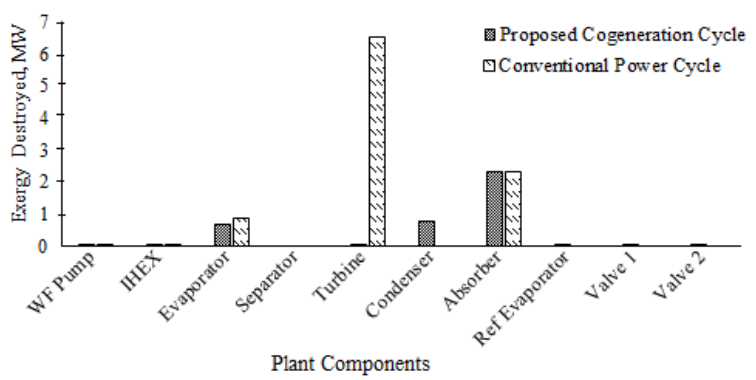

Figure 10 Exergy Losses by Component

1.11 Comparison between the Proposed Cycle and Conventional Absorption Power Cycle

A simulation of a conventional absorption power-only cycle was performed to serve as a basis for comparison with the proposed combined absorption power and refrigeration cycle. In order to obtain a more valid comparison, between these two different types of cycles, the combined cycle would have to be configured in such a way as to imitate operating as a power cycle. This was easily achieved by dividing the exergy of cooling by the COP of a reversible refrigeration cycle, which is a Lorentz cycle in this case. By so doing, we would be replacing the cooling output by the minimum mechanical power required to produce the same amount of cooling that would be 
achieved by a reversible refrigeration cycle. For nonideal situations, however, this is termed as the practical COP since a reasonable COP rather than that of the reversible refrigeration cycle is used. The $\mathrm{COP}_{\mathrm{Rev}}$ in equation 3.53 and equation 3.54 are replaced by $\mathrm{COP}$ practical the effective efficiencies take the form:

$$
\begin{aligned}
& \eta_{\text {theff }}=\frac{\left(W_{\text {nat }}+{ }^{E_{c}} f_{C o p_{\text {practical }}}\right)}{Q_{h}}
\end{aligned}
$$

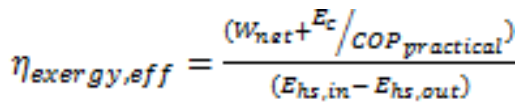

The equations (20) and (21) were used to obtain the effective thermal efficiency and effective exergy efficiencies of the combined cycle that provided a more valid basis for comparison with the power-only cycle. The results of effective thermal efficiency of the combined cycle was compared to the thermal efficiency of the power cycle based on parameters such as varying heat source temperature, and concentration of the basic solution. Fig.11 shows that the cogeneration cycle gives higher thermal efficiency than the power-only cycle, and this is the case for the entire range of hat source temperatures that were applied. Fig.12 also indicates that the exergy efficiency for the combined cycle is higher than that of the power cycle for all the heat source temperatures that were applied.

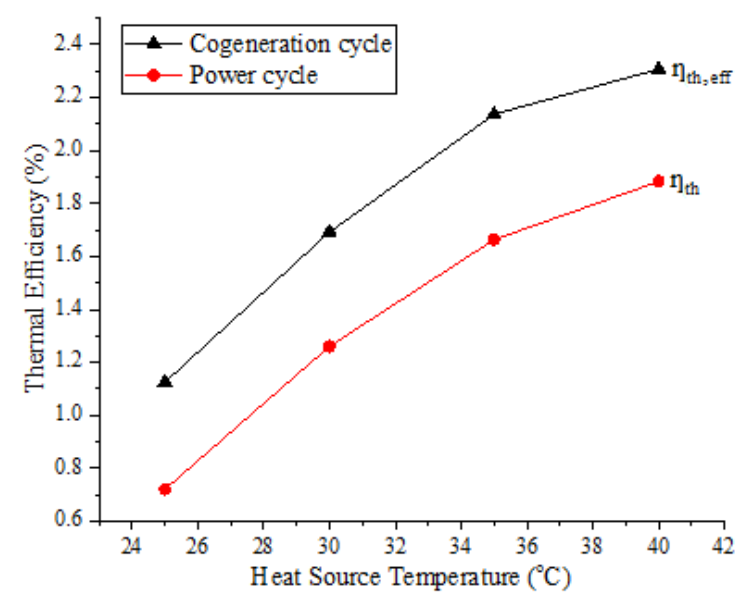

Figure 11 Comparing the Thermal Efficiency of The Cogeneration Cycle and A Power Cycle

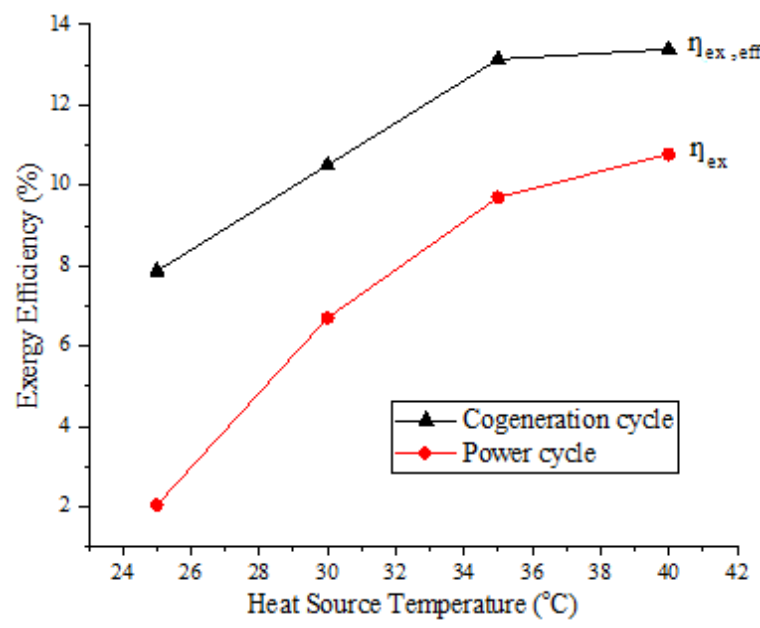

Figure 12 Comparing the Exergy Efficiency of The Cogeneration Cycle and A Power Cycle

\section{CONCLUSIONS}

The minimum temperature difference $(\Delta \mathrm{T})$ between the warm surface and the cold bottom layers of the ocean that is applicable to OTEC systems is $20^{\circ}$. The performance of OTEC systems is dependent on the temperature of the heat source (warm surface sea water) as well as the temperature of the cold reservoir (cold sea water). The $\mathrm{NH}_{3} / \mathrm{H}_{2} \mathrm{O}$ mixture working fluid makes it possible for absorption-condensation, which in effect, makes it possible to obtain cold water at a reduced depth of about $600 \mathrm{~m}$. The refrigeration output of the cogeneration system makes it possible to increase $\Delta \mathrm{T}$ by providing further cooling at the absorber. Two cases were presented with respect to the depth of cold water capture. Case I and Case II represented configurations of the OTEC-cogeneration cycle in which the cold water is captured at $1000 \mathrm{~m}$ and $600 \mathrm{~m}$ respectively. Under simulation conditions of $30^{\circ} \mathrm{C}$ warm surface sea water temperature, $10^{\circ} \mathrm{C}$ cold sea water temperature captured at a depth of $600 \mathrm{~m}$, and an optimum working fluid basic solution concentration of $0.40 \mathrm{NH}_{3} / \mathrm{H}_{2} \mathrm{O}$ Case II produced a net power output of $31 \mathrm{~kW}$ and a refrigeration output of $360 \mathrm{~kW}$. The thermal efficiency and exergy efficiency under those conditions were $1.94 \%$ and $13.78 \%$ respectively. Case I, on the other hand produced a net power output of $3 \mathrm{~kW}$ with thermal efficiency of $0.4 \%$ and an exergy efficiency of $3.8 \%$. The low net power output of the Case I cycle is attributed to the high rate of energy consumption that accompanies the drawing of cold water from the ocean depths, which reduces the net power output of the cycle.

The temperature of the heat source was also varied from $25^{\circ} \mathrm{C}$ to $30^{\circ} \mathrm{C}, 35^{\circ} \mathrm{C}$ and $40^{\circ} \mathrm{C}$ based on the assumption that the temperature of the warm surface sea water can be increased by using external methods to heat up the warm sea water in order to achieve higher cycle outputs. At a heat source temperature of $30^{\circ} \mathrm{C}$, the cycle for Case II produced a net power output of $42 \mathrm{~kW}$, a refrigeration output of $370 \mathrm{~kW}$, a

WWW


thermal efficiency of $1.87 \%$ and an exergy efficiency of $13.69 \%$. When the heat source temperature was increased to $35^{\circ} \mathrm{C}$, the cycle produced a net power output of $60 \mathrm{~kW}$, a refrigeration output of $402 \mathrm{~kW}$, a thermal efficiency of $2.38 \%$ and an exergy efficiency of $13.98 \%$. Finally, at a heat source temperature of $40^{\circ} \mathrm{C}$, the cycle produced a net power output of 69 $\mathrm{kW}$, a refrigeration output of $417 \mathrm{~kW}$, a thermal efficiency of $2.61 \%$ and an exergy efficiency of $14.91 \%$. Although the thermal efficiency of OTEC systems is generally low, it is important to take note that seawater, which is the "fuel" which drives the system, is virtually free. It is therefore, more appropriate to evaluate the cycle's performance using the concept of exergy efficiency. The reason being that an evaluation based on the concept of exergy efficiency takes into consideration the availability of the heat source i.e. the amount of thermal energy from the warm surface sea water that is used up by the cycle and not the entire heat input.

\section{Nomenclature}

Symbols

E Change in exergy, $\mathrm{kW}$

$E_{c} \quad$ Change in exergy of cooling, $\mathrm{kW}$

$g \quad$ Acceleration due to gravity, $\mathrm{ms}^{-2}$

$h \quad$ enthalpy, $\mathrm{kJkg}^{-1}$

$h \quad$ height, $\mathrm{m}$

$m \quad$ mass, $\mathrm{kg}$

$\dot{m} \quad$ Mass flow rate, $\mathrm{kgs}^{-1}$

$p \quad$ Pressure, bar

$P_{h} \quad$ Pump Hydraulic Power, kW

$Q \quad$ Heat transfer, $\mathrm{kW}$

$S \quad$ Entropy, $\mathrm{kJkg}^{-1} \mathrm{~K}^{-1}$

$T \quad$ Temperature, ${ }^{\circ} \mathrm{C}$

$T_{o} \quad$ Absolute temp. of reference point, $\mathrm{K}$

$W_{\text {net }} \quad$ net power output, $\mathrm{kW}$

$W_{p} \quad$ pump work input, $\mathrm{kW}$

$\begin{array}{ll} & \text { Subscripts } \\ A B S & \text { Absorber } \\ C W & \text { cold seawater } \\ C W P & \text { cold seawater pump } \\ E V A P & \text { evaporator } \\ I H E X & \text { internal heat exchanger } \\ \text { REVAP } & \text { refrigeration evaporator } \\ \text { SEP } & \text { flash separator } \\ S P L & \text { splitter } \\ \text { TURB } & \text { turbine } \\ \text { VLV } & \text { throttling valve } \\ \text { WFP } & \text { working fluid pump }\end{array}$

WW warm seawater

WWP warm seawater pump

\section{REFERENCES}

[1]. Masutani, S.M. and P.K. Takahashi, Ocean Thermal Energy Conversion. Fuel and Energy Abstracts, 1999. 37(3): p. 201

[2]. Faizal, M. and M.R. Ahmed, Experimental studies on a closed cycle demonstration OTEC plant working on small temperature difference. Renewable Energy, 2013. 51: p. 234-240.

[3]. Yang, M. and R. Yeh, Analysis of optimization in an OTEC plant using organic Rankine cycle. Renewable Energy, 2014. 68: p. 25-34.

[4]. Yamada, N., A. Hoshi, and Y. Ikegami, Performance simulation of solar-boosted ocean thermal energy conversion plant. Renewable Energy, 2009. 34(7): p. 1752-1758.

[5]. Bombarda, P., C. Invernizzi, and M. Gaia, Performance Analysis of OTEC Plants With Multilevel Organic Rankine Cycle and Solar Hybridization. Journal of Engineering for Gas Turbines and Power-transactions of The Asme, 2013. 135(4): p. 042302.

[6]. Li, M., et al., Construction and preliminary test of a lowtemperature regenerative Organic Rankine Cycle (ORC) using R123. Renewable Energy, 2013. 57: p. 216-222.

[7]. Vijayaraghavan, S. and D.Y. Goswami, On Evaluating Efficiency of a Combined Power and Cooling Cycle. Journal of Energy Resources Technology-transactions of The Asme, 2003. 125(3): p. 221-227.

[8]. Ayou, D.S., et al., Analysis and simulation of modified ammonia/water absorption cycle for power and cooling applications. International Journal of Low-carbon Technologies, 2013. 8.

[9]. Tamm, G., et al., Novel Combined Power and Cooling Thermodynamic Cycle for Low Temperature Heat Sources, Part I: Theoretical Investigation. Journal of Solar Energy Engineering-transactions of The Asme, 2003. 125(2): p. 218-222.

[10]. Sadrameli, S.M. and D.Y. Goswami, Optimum operating conditions for a combined power and cooling thermodynamic cycle. Applied Energy, 2007. 84(3): p. 254-265. 